\title{
Exhibition of a Tesla Coil
}

This content has been downloaded from IOPscience. Please scroll down to see the full text. 1897 Proc. Phys. Soc. London 1661

(http://iopscience.iop.org/1478-7814/16/1/312)

View the table of contents for this issue, or go to the journal homepage for more

Download details:

IP Address: 128.111.121.42

This content was downloaded on 03/09/2015 at 02:40

Please note that terms and conditions apply. 


\section{Discussion.}

Prof. Threlfall said he had come to the same conclusion as Prof. Lodge as to the advisability of diminishing the number of contact points in the coherer. He had endeavoured to produce longer and more persistent waves, and thus to set afield greater effective energy. It was desirable to keep the waves as parallel as possible. He thought there was some probability that the wave-fronts could be altered and rendered more conformable by a process of diffraction.

Mr. Rutherford also had found it best to work with long waves. $\mathrm{He}$ fully appreciated the advantage of increasing the capacity of the oscillator by extending the surface of the metallic plates.

Mr. CAMPBELL-Sw'inton asked whether experiments had been made to verify Hertz's results as to the influence of reflectors behind oscillators and receivers. He had found them disadvantageous. A single wire behind either apparatus seemed partially to annul the effect. He also asked whether Prof. Lodge had observed the extraordinary sensitiveness of coherers to small changes of current in neighbouring circuits.

Prof. Longe, in reply, said he had observed the sensitiveness to slight sudden variations of current referred to by $\mathrm{Mr}$. Campbell-Swinton ; for instance, when electric lamps were switched on and off. The effect of mirrors had been studied by Prof. Fitzgerald. They required to be of large dimensions as compared to the oscill itor and receiver, otherwise the true reflections were not obtained.

\section{XI, Exlibition of a Tesla Coil. By Prof. Silvanus} 'Thompson, D.Sc., F.R.S.*

THIs apparatus is intended to replace the two inductioncoils and spark-gap arrangements used by Mr. Tesla for highfrequency experiments. It consists of an induction-coil, with a separate self-inductance coil in the primary circuit. This self-inductance coil is also used as an electromagnet for the separate interrupter of the primary circuit. A condenser of 2.27 microfarads capacity is connected between one end of

$$
\text { * January 21, } 1898 .
$$


the primary coil and one terminal of the interrupter, so as to include both of them between its terminals. The primary consists of 5 turns of copper strip. The secondary has 2000 turns of thick wire. The supply current, about half an ampere, may be taken from the electric-light mains at almost any voltage from 50 to 200 , direct or alternating.

\section{Discussion.}

Prof. LOD GE said that he believed Sir W. Crookes had found it work quite well at 10 volts. He pointed out also that if the straight discharge rods at the spark-gap were free to slide, the discharge drove them back into their sockets.

Prof. Firzarrald said it was stated at Toronto that the spark was broken at the interrupter when the condenser was charged, and that by the time the condenser was ready to discharge, the contact at the interrupter had been made again. It had seemed to him at first that the condenser discharges and surgings must take place at a rate far higher than the period of the mechanical movement of the interrupter; but he perceived afterwards that it was not so.

Prof. HERSCHEL asked if such an apparatus was suitable for work with Röntgen rays.

Dr. Thом pson, in reply, congratulated Mr. Tesla upon the perfect working and compactness of his invention. The present form was not suited for Röntgen ray experiments, with ordinary focus-tubes, but Mr. Tesla had designed a special tube that was excellent for that purpose.

XII. Winter Observations on the Shadow of the Peak of Tenerife, with a new Method for measuring approximately the Diameter of the Earth. By Rev. T. C. Porter, M.A.*

[Abstract.]

THE method consists in observing the shadow cast by the Peak upon the sea, and measuring the time that elapses between the moment when the apex of the shadow touches

* Read February 26, 1848. 